\title{
Discretionary Power as a Political Weapon Against Foreigners
}

\author{
Alexis Spire \\ French National Centre for Scientific Research, CNRS, alexis.spire@ehess.fr \\ DOI: http://dx.doi.org/10.5324/eip.v14i2.3479 \\ (cc)BY \\ This is an open access article distributed under the terms of the Creative Commons \\ Attribution 4.0 International License, which permits unrestricted use, distribution, and \\ reproduction in any medium, provided the original author and source are credited.
}

The administrative practices of officials who process the admission of immigrants show severe variations in the ways in which migration policy is enforced on the ground. For the author, inequality of treatment lies in the very hierarchy of tasks and services of what he dubs, following Pierre Bourdieu, the immigration "field". According to the author, the governments' securitizing priorities favour the sort of suspicion towards foreigners that the media then reproduces, thus authorizing socalled street-level bureaucrats to act with great leeway with regard to immigrants. Under pressure, governments implement what the author calls a "trompe-l'oeil policy" that explores the ambivalence between international and domestic law: while the state enforces repressive laws that apparently comply with fundamental human rights, it leaves to low-ranking civil servants enough discretion to make those rights ineffective. This point is the author's central contention. The arbitrariness of these officials is neither contingent nor accidental: it actually constitutes a purposive "front-line policy" to enlarge the discretionary power of street-level bureaucrats in charge of regulating admissions. Unequal treatment comes in three flavours in this context. First, officials are asked to ensure that each right granted to a foreigner will not threaten the national order, which means the economic, social and political order. They are therefore in a position to judge the suitability of each application in view of their own arbitrary interpretation of what such "threats" consist of. The question of discretionary power is in this way intimately linked to the problem of equality before the law. Second, the scarcity of material and human resources allocated to services in charge of welcoming migrants starkly contrasts with the expenditure incurred to deport foreigners. Inequality also arises from how agents perceive users and the leeway they have to implement the law. Third, inequality is related to foreigners' abilities and means to challenge discretionary power, especially through the legal tools they use or through legal intermediaries. The author thus concludes that such "front-line policy" has increasingly been used as a weapon against migrants, especially since the early 2000s, when immigration and detention policies were generalized in France. More broadly, in Europe as well as in United States, immigration reforms have made greater use of detention and focused on enforcement rather than on hosting programs and services for asylum seekers. But they have also strengthened the role of legal intermediaries. Hence the need to 
investigate how discretionary power is challenged as it sheds light on the power relations between states and migrants.

Keywords: foreigners, discretion, sociology, participant observation, front-line policy, illegalism, jobs, insecurity, legal intermediaries

Since the collapse of the states of Iraq, Libya and Syria, European countries are facing increasing immigration flows. In response to this unprecedented situation since the Second World War, European governments have heavily increased controls at their borders and tightened the refugees' rights of entry into their territory. This has been carried out in the framework of an intensified combat against terrorism (Bigo 2014). Frightened by what they call populism, left wing politicians have refused to imagine any plausible alternative to the selective closing of borders. ${ }^{1}$

By drawing the public's attention to illegal immigration, politicians and journalists have succeeded in rendering suspect any foreigner who applies for documents. They have also extended mistrust to those who help accommodate and give support to the undocumented (Dahlberg 2013). Terrorist threat has been used as an argument to reinforce the power of the police force and to lighten controls by the legal authorities. Consequently, discretionary power of state employees has substantially expanded, while the legal guarantees intrinsic to the rule of law and international conventions that protect refugees are - theoretically - still upheld. This spiralling into repression leads European governments to the following contradictions: How to constantly improve results in tackling illegal immigration while abiding by international laws? How to deter the migrants who have fled persecution while continuing to rely on the Geneva Convention? How to drastically limit family reunions without contravening the fundamental right to lead a normal family life as defined in the EU human rights convention?

In order to solve those contradictions, the government implements a trompel'oeil policy. On the one hand, the state reinforces repressive laws that seem to comply with fundamental human rights. On the other hand, it consigns to lowranking civil servants the discretion to make those rights ineffective. This is what one could call a "front-line policy" (Spire 2012). It consists in enlarging the discretionary power of all street-level bureaucrats in charge of immigration and in allocating one main task to them: to ensure that each right granted to a foreigner will not threaten the national order, that is to say the economic, social and political order. The question of discretionary power is tightly connected to the problem of equality before the law. Following the work of Michael Lipsky (Lipsky 1980), I would like to point out that unequal treatments in implementing the law result partially from the tasks carried out by street level bureaucrats. Understanding French immigration policy means getting closer to the daily practices of lowranking civil servants with foreigners.

\section{A Sociological Approach to Discretionary Power}

Discretionary power, a term generally used by lawyers, refers to the possibility "to exercise free choice, constrained only by legal limits" (Davis 1969: 4). More broadly, 
this term describes "the sphere of autonomy" (Galligan 1990: 8) within which state agents are allowed to make decisions according to their personal judgement and assessment, provided that they remain within the boundaries of the law. The concept of discretionary power finds itself intrinsically linked to the fuzziness of legal language. A sociological approach to this power consists in highlighting social criteria that surround this "legal uncertainty" and the effects it generates.

\section{Two Types of Discretionary Power}

From a legal perspective, discretionary power refers to the sphere of autonomy in which civil servants are allowed to make their own decisions while implementing the law. This discretionary power is consubstantial with the bureaucracy to the extent that the law is always supposed to lay out general principles that need to be reinterpreted. From this perspective, the discretionary power refers to two types of realities.

On the one hand, discretionary power refers to an interpretation of the law that becomes incarnate in decrees and regulatory texts. This power comes from highranking civil servants especially appointed by the government to explain to streetlevel bureaucrats how to interpret legal texts. This "bureaucratic politics" (Allison and Halperin 1972) can be understood as a result of the bargaining between several actors positioned hierarchically at the top of the administration. On the other hand, discretionary power refers to a singular decision made to implement the legal norm for an individual case, such as when an authorisation needs to be granted or some benefits or favour given. The development of the first type of discretionary power was spurred in the historical period between 1945 and 1975 in France. This rule of the administrative circular (in contrast to the rule of law) has nevertheless sharply decreased since the end of the 1970s. The increase in appeals in administrative courts against those circulars has greatly limited discretionary power used by highranking state officials in the drafting of the rules ${ }^{2}$.

Furthermore, most circulars are nowadays accessible online and those which are most conflictual fuel the political debate. Top civil servants in charge of writing those texts are thus constrained to use euphemism and leave to intermediary agents the task of implementing what the top civil servants have been unwilling to clarify. The scope of the inner rules - that is to say the first type of discretionary power has been limited by the publication of circulars and by the judicial controls. This evolution accorded greater policy leeway to street-level bureaucrats - that is to say an extension of the second type of discretionary power - for a daily implementation of the legal texts.

Several methods can be considered to understand this structurally unequal relationship between migrants and street-level bureaucrats, which I call the "Frontline Policy".

\section{Participant Observation at the 'Préfecture'}

Analysing how immigration control is actually implemented is a difficult task because state agents refuse to be observed by an outsider when at work. Whereas it is always possible to study the immigration policy with a method based on interviews, such an approach would be limited to the officials' speeches that teach more about how they view their jobs rather than about what they actually do. ${ }^{3}$ 
In order to be able to confront state agents with their job practices, I chose to use a "participant observation" method, which means immersing oneself in an alien social reality in order to observe social phenomena while at the same time participating in it (Bourdieu 2003). That is why I volunteered to become a "temporary clerk" at a desk in charge of receiving asylum seekers and deciding whether they have the right to stay in France. Every year, prefectures in the biggest cities look for temporary workers to respond to the influx of asylum seekers at certain times of the year, especially during the summer when the prefectures are understaffed due to vacations.

The acquaintances that I had made while doing my $\mathrm{PhD}$ helped me to apply for one of those "summer jobs" usually reserved for the agents' children. To solve the "unending dialectics between the role of member (participant) and stranger (observer and reporter)" highlighted by Hughes (1984: 503), I opted for the status of being "publicly a participant and secretly a reporter".

Thanks to my PHD student status on immigration policies, I was able to maintain a certain ambiguity about the reasons I wanted to obtain this job, in order to be able to conduct a "covert ethnography" (Calvey 2008). For the people I worked with, it was clear that my application for a summer job as a clerk was a way to look at the behaviours of migrants. However, it was inconceivable for them that I might be there to observe my colleagues. I played on this ambiguity by focusing on the fact that my foreign language skills could be helpful for a task that consists of receiving migrants. I never openly explained my intention to investigate the frontline workers' job practices. Thus, for a full month, I worked in a prefecture service in charge of granting and renewing residence permits to asylum seekers.

As a recently recruited front-line agent, I was at first unsettled by a type of job I did not know at all and by a form of pressure that I had not experienced before. Receiving foreigners does not entail any physical exertion because clerks remain seated for most of their working day. However, I felt a mental weariness related to the never-ending flow of people who hardly speak any French and for whom complex procedures and unfamiliar situations must be explained. Front-line agents must also translate the documents drafted in bureaucratic lingo for an audience that can speak minimal French.

These daily situations are what agents usually call "front-line pressure". This term refers to the high number of foreigners waiting in line (as soon as the prefecture opens in the morning, the maximum number of people that can be treated in a day is generally already reached) and to the maximum number of files that can be processed in one day. Each clerk was required to process 27 files daily, but this number could be adjusted according to the complexity of the dossiers.

These statistical constraints are normal in immigration control services but they are more constraining at an asylum reception desk, due to the language barrier. My English and German skills were of no use when I needed to explain to the migrants how to fill in their forms because they spoke languages I do not command. At any rate, my colleagues were across the board eager to remind me that I was supposed to speak only in French, as a local representative of the French administration. The front-line pressure was also intensified by the constant scrutiny of the managers, embodied by the head of staff who stayed behind the front line so that they could monitor the performance of the clerks and the quality of their work. This supervisory practice can be compared to the Panopticon described in Foucault's 
writings (Foucault 1977): the head of staff can watch every employee at work but the employees do not know if they are being monitored. Despite all the difficulties and effort integral to the clerk position, I also realized the advantages it offered in comparison to other services in charge of welcoming the public: since asylum seekers are not treated as national citizens, the clerks interacting with them enjoy a high degree of autonomy in their daily tasks.

This participant observation also gave me access to the daily sociability of streetlevel bureaucrats: discussion topics during the breaks, jokes, comments on the behaviours of migrants. This informal dimension of their work is generally absent from the literature since scholars focus on the professional experiences of clerks. However, stories and jokes shared by front-line agents are insightful. When the working day was over, some of my colleagues used to mimic the Romanians who had burst in tears to make fun of them. It was also a way to assert the clerks were not fooled. These private jokes tell more about how the agents perceive the asylum seekers than some long and endless abstract discourses on the different treatments reserved for asylum seekers according to their nationalities. As in many other work situations, the use of humour helps to reinforce the cohesion of the group of colleagues: through different sorts of jokes, they want to show their unwillingness to feel sorry for asylum seekers, whom they constantly suspect of faking unwellness in order to get more than they are entitled to.

A couple of years later, I led an ethnographic study in the visa service at the French consulate in Tunis. This experience helped me to add nuance to my ideas about discretionary power. Like their counterparts in the prefectures, agents in visa sections of the Consulate have to make a significant number of decisions that are crucial for the foreigners who apply for a residence permit. But in their daily work, they are confronted with double binds.

On the one hand, they have to assess each claim, the "migratory risk" that the visa seeker represents, taking into account such criteria as their family situation, social status, education, and income. On the other hand, the head of the service is supposed to maintain good relationships with the Tunisian authorities, which implies giving full and sympathetic consideration to visa applications from persons close to the regime. Pointing out the possible contradiction between these two goals helps in understanding what is at stake in the daily attributions of privilege. In the city of Tunis, exemption files for issuing visas are treated in a separate office and can number 20,000 out of a total of 80,000 visas annually. This high number of waivers goes well beyond classifying these actions as "corruption": circumventing the law in exchange for compensation is not the exception but is clearly part of an institutional system of exemptions.

At the very top, the consul in person has to comply with demands emanating from local authorities every time diplomatic issues are at stake. Some special claims are directly managed by the ambassador who, after assessing the influence of the claimant, can decide to grant an exemption such as a visa free of charge. The office manager also has to deal with exemption claims submitted by various ministries or lawmakers. These requests for exemptions can either be for professional reasons, such as an artist or a businessman invited by the authorities, or for personal reasons: for instance, the housemaid's cousin or the au-pair's husband when he or she is recommended by an authority. The decision-makers are also likely to grant claims for their own close relatives or for staff who work in their office. Hence, privileges 
are not granted on an exceptional basis in these cases, and they play a key role in two ways. On the political level, exemptions enable the French government to maintain good relations with the local authorities. At the social level, these privileges standardise the practices of the French state with those performed by the local authorities. Studying daily life in a Consulate sheds light on the use of a hybrid culture, composed of arrangements between state central institutions and some local power practices.

\section{Discretionary Power and Differential Management of Illegalisms}

A sociological analysis of discretionary power does not limit itself to highlighting the discrepancy between the law and its implementation. At stake are all the social, economic and institutional determinants that influence the daily implementation of the law and which warrant analysing.

Rejecting legal formalism, Pierre Bourdieu pointed out that the regulatory measures of the law are reinterpreted and redefined by the agents responsible for implementing them. According to the agents' dispositions and interests, they can use their scope for manoeuvre differently, ranging from strictly implementing to exempting or even transgressing the law (Bourdieu 1990). Following the same logic of inquiry, one needs to study the background, career and social trajectory of the front-line agents who are in charge of implementing discretionary power, taking into account their present and potential situation in the structure of distribution of power (inside the bureaucratic field) as well as on their professional practices.

However, taking into account front-line agents' social background is not enough to explain all the forms assumed by discretionary power. It is possible to study discretionary power within a bureaucratic field, by placing immigration policy, its institutions and agents in the broader context of "the extension of bureaucracy and the strengthening of movements for political rights" (Bourdieu 1987). The implementation of the law always produces power struggles that involve different players and institutions. Furthermore, the room for manoeuvre given to state agents does not reduce itself to the clear-cut alternative between permission and prohibition on the one hand, and between the strict implementation of and exemption from the law on the other. When it comes to immigration policies, a large part of the differential management of illegalisms depends on the time-related aspect of the law. Bureaucratic practices obviously depend on legal disposition and administrative rules, but they cannot be understood outside of the time span in which they are implemented (Moore 1963; Bergman 1992). First of all, the strategic use of time implies for state agents the ability to keep one type of foreigner waiting while a swift decision will be made for another type of asylum seeker. With this in mind, time is the most conspicuous manifestation of bureaucratic domination in an administrative office.

Time is also used as a key variable in the pace of decision-making when granting a residence permit or enforcing sanction. Delaying one's decision is more or less a mundane means to keep a user in legal uncertainty to test their determination. Combining ethnographic inquiry with studies on archived files can be helpful in showing the importance of time in implementing immigration policy: the strategic use of time manifests itself, conspicuously, when observing the waiting lines at the counter and, retrospectively, when delving in archived individual files which show the succession of residence permits issued (Spire 2008). 
In other state offices that deal with all types of users (not only foreigners), discretionary power takes on a slightly different meaning. It does not limit itself to the unilateral power of a state agent but rather leaves room for users to negotiate. Decisions and sanctions taken by front-line agents also depend on the tools they have at their disposal and the collective norms that are accepted in each office (Calavita 1992).

One can then extract a two-tier variable system in the discretionary power of street-level bureaucrats. First, within the same administration, the implementation of the law can have a different effect according to the social background of its frontline agents and to their role in the work organisation. Secondly, the everyday interpretation of the law can also change from one administration office to another, according to the type of users they welcome. Discretionary power has to be analysed in the frame of interactions between the civil servants who implement the law and the users subject to administration controls, taking into account the possible presence of actors (non-governmental organizations, social workers or lawyers) who are likely to step in. This dynamic of interactions enables state agents to constantly redefine the line between what is legal and what is not, or between what is acceptable or not.

\section{The Front Line for Foreigners}

The importance given to immigration in public debate clearly contrasts with the relegation imposed onto the institutions in charge of dealing with foreigners. It is uncommon to meet workers who deliberately apply for front-line desk jobs at prefectures or in other places dedicated to grant visas. The discredit given to this kind of job is an old story indeed. In the bureaucratic sphere, the value given to a desk is related to the type of people who use it; front-line immigration workers are belittled because of the depreciated status of foreigners coming to the prefecture gates. This sort of relegation is not only symbolic; it is also visible in the working conditions that are less advantageous than in any other service. In fact, services in charge of immigration must deal with a tremendous number of files and a lack of working tools and staff. A parallel (or more precisely a homology) may well be drawn between the social position of civil servants in charge of dealing with foreigners and the social status of their claimants.

Beyond this relegation visible from one department to another, one can nevertheless notice substantial variations according to the workstation and the task assigned to each agent. Working at a front-line desk implies interacting face-to-face with migrants, whereas working in the back office requires the ability to make decisions after reading a file. Managing a service in charge of immigration implies being able to establish norms based on juridical text, in order to adapt the practices to every case. Civil servants who manage services dealing with foreigners are in a lower position compared to their colleagues with similar responsibilities in other departments. However, their managers allow them to implement their discretionary power. This combination of relegation and autonomy is one of the characteristics specific to the task of the agents in charge of immigration. 


\section{Dominated Dominants}

In many institutions, the desk in charge of receiving foreigners is located well away from other services. Such a separation enables the agents in charge of immigration to hide, even to make invisible, the conditions of reception offered to the migrants. The contrast between the situation outside the buildings, where foreigners endure scuffles to keep their place in line, and the quiet atmosphere inside the building where uniformed police officers enforce silence. Only people who have waited for hours or those who have paid another asylum seeker up to $€ 100$ for a ticket are allowed to enter the building. The obstacles in accessing the building are typical of immigration services and offer a concrete glimpse at the power of the bureaucrats in charge of immigration. Foreigners are obliged to comply with the rule of bureaucracy throughout the whole claim process, even if these rules prevent them from asserting their rights.

The deterioration of the prefecture buildings and the tools at the staff's disposal confirm the street-level bureaucrats' feeling of being abandoned; some will even confess to feeling sacrificed by their managers. Offices are very often too cramped to receive such a large number of people, the working tools are faulty and the classic cliché of files spilling out of cabinets and drawers can be seen in every office. Yet the stigma attached to immigration services is not only visible in external signs. As with any other French bureaucratic civil service, women form the majority of the staff throughout the ranks. The denigration attached to the task of receiving foreigners enables women to become office managers more readily than in other office jobs. ${ }^{4}$ Generally, the agents who work in such services are more likely born abroad, naturalized or from the French Antilles than agents in other more prestigious services. This over representation is partly related to their position of inferiority in the French bureaucracy. As in the manufacturing industry, dirty work is given to the most stigmatized people in the informal relation network (Hughes 1952; Pedace 2006). The excessive numbers of bureaucrats who are people of colour is not only a sign of their stigmatisation; they also reveal the will of their managers to use them as a shield against being accused of unfair treatment, discrimination, or racism.

\section{"Dirty work"5 and Respectable Tasks}

Theoretically, the prefects or one of their representatives are legally entitled to decide, in the name of the state, who among the foreigners will be allowed to stay on the territory, who among the claimants will be granted a resident permit and who must be deported. In day to day operations, those practices are assigned to front-line civil servants who, according to their seniority and to how their position is valued in the service, exercise this discretionary power.

First of all, the differentiation of the tasks is based on the physical proximity of the agents to the migrants. The least valued position is also the one that deals with taking the claimants' fingerprints because it implies physical contact with the foreigners. In order to avoid any physical contact, some staff decide to wear a facial mask and gloves. Furthermore, they often have to take the prints more than once since every faulty procedure triggers an error message that pops up on the screen, for instance "too light", "too dark" or "the print is too small". The task is also impossible to perform if the foreigner has burnt or roughened their fingers in order to avoid being registered. Working behind a desk, on the other hand, enables staff 
to remain seated and to maintain distance from the migrants. It is true that a continuous and direct interaction with asylum seekers arriving en masse, one after the other, influences the working conditions. However, unlike other claimants, asylum seekers rarely challenge the procedure that is imposed on them. For instance, migrants who sleep part of the night in front of the prefecture gates and then wait for hours inside do not dare to protest when an agent, at the end of the day, announces that they have to return another day, usually because the streetlevel bureaucrats have not been able to process all the claims they have. For frontline agents, this pressure due to the huge number of claimants is thus counterbalanced by the feeling of superiority they have over the public they receive.

As in other government services, making decisions is more valued than receiving users (Dubois 2016). Decision-making positions are usually located separate from reception desks, so that the agent in charge of making decisions is not in direct contact with the claimants. Remarks by agents about the odours and noise related to the asylum seekers, in contrast with the calm and serenity of the other offices where decisions are made, reinforce the disparity between the two roles. Officially, this divide between offices where decisions are made and where claimants are received is aimed at avoiding corruption. In practice, the split has other functions. First of all, claimants are deprived of the possibility to challenge and negotiate official decisions. When their claims have been rejected and they want to know why, the agent can easily turn them away saying that the decision was made by one of their colleagues or managers. This separation also enables the agents to base their decisions only on the information contained in the file, without considering the reasons and arguments given by the claimant. Finally, this division of tasks relieves every agent in the decision process from any responsibility and conceals their role. Front-line agents are however not totally without power in the decision-making process. In a consulate, they frequently suggest the duration of the visa that will be granted. In a prefecture, they can lengthen the waiting time before a claimant is granted a residence permit by moving their file to the bottom of the pile if they find the claimant unfriendly or impolite.

The major part of discretionary power is given to office managers who supervise the reception and decision tasks. We can call them "go-between" agents in the dual meaning of the term: they work between high-ranking civil servants and front-line agents, and they operate between the government and local offices. As Goffman pointed out, this type of mediator "learns the secret of each side and gives each side the true impression that he will keep its secret; but he tends to give the false impression that he is more loyal to it than to the other side" (Goffman 1956: 93). This in-between position provides office managers with considerable discretionary power. Through their oral instructions, they develop informal and practical rules to manage their work and reconcile the discrepancy between lived realities and official regulations. They interpret the law for front-line agents. Legally, for instance, foreigners can use any means to prove that they live in France permanently but in practice, state officials frequently reject their claims for a "lack of residence evidence", following the oral instructions given by the management. Office managers, as go-between agents, thus build a complex patchwork of formal and informal rules that are adapted each for each individual case. 


\section{Too Much Power?}

In their daily work, street-level bureaucrats influence migrants' lives dramatically. They can either accept or reject migrants' continued residence in France, authorize or prohibit their employment or reuniting with their wives and children. Regardless of whether they work at a front-line desk, in the back office or as managers, state officials feel they have a special power. This sense is reinforced by the way officials use their authority over migrants who rarely are aware of their rights. ${ }^{6}$

Front-line agents can add remarks in the margins of the claim form, but the final decision passes on to another agent in the back office who will not necessarily take them into account. Here is an example I witnessed at the front-line desk of a prefecture: it was the case of a Lebanese priest who applied for a one-year residence permit. Once the interaction was over, the lady at the front desk wrote "likeable" in the margin of the form. However, the decision remained uncertain for the state official who had to deal with this file:

When we have to make a decision like this or when it is about regularisation for family reasons, we need to think thoroughly before reaching the decision, because if we grant the authorisation once, we will have to renew it again and again... The problem is that we are a bit lost in our job, we have all the necessary texts but they rarely match the cases we face (Interview with a prefecture officer).

The loophole in the law increases the discretionary power of the state officials. Since the priest did not provide any documents to prove his source of income, he was granted a short three-month permit, so that he had time to gather the additional documents and that other administrative branches were consulted about this case. This way of keeping claimants on temporary resident status, full of uncertainty for them, has become a rule for the services in charge of immigration. The choice to extend temporary status and postpone approval of a permanent residence permit is a way to test the migrant's resolve since it would be illegal to plainly dismiss their request. Besides, such a bureaucratic use of time is a limit imposed on the claimants in their rights to challenge a decision, and it maintains the discretionary power of street-level bureaucrats for a future decision. As migratory flows are increasingly controlled, the risk of granting a permit to a foreigner for the wrong reason is considered greater than refusing it for unlawful reasons. In one case, the agent risks being gainsaid by their managers for not being severe enough, whereas in the other case agents have little chance to be blamed for being too "strict", unless the case is brought to court, which is not an issue for services in charge of immigration.

The discretionary power of front-line agents in the immigration services is not limited to their ability to implement the circulars. What could be understood as an interpretation of the text could be indeed a plain violation of the law. In some prefectures, front-line agents regularly ask asylum seekers to show documents that will prove their identity, even if the Geneva Convention exempts them from doing so. Some migrants are not aware of this text, but even if they do know the rule, they do not regard it as an imperious command but as a constraint that could harm the efficiency of their service. In such a case, the law plays a secondary role, sometimes even a subsidiary role.

The use of illegal practices is clearly justified and accepted in the name of efficiency and to tackle fraud. During a face-to-face encounter at a front desk, with no written evidence attached, abiding the law is experienced as a superfluous 
constraint in comparison with the control mission. Front-line officials' mistrust of the law, widely spread among the police force, is even more pronounced when someone works with claimants who do not belong to the national community. At consulates, where visa claimants do not know their rights and are only infrequently accompanied by legal counsel, this way of regarding the rights of migrants - as hindering immigration control processes - is commonplace. The temptation to circumvent the law under the guise of tackling fraud attempts is reinforced by the conviction that foreigners are not aware of their rights.

\section{The Transformations of the Front-line Policy}

In the domain of immigration policy, the role attributed to the street-level bureaucrats who interpret government circulars has always been strategic (Engbersen and Broeders 2009). Those agents maintain a climate of legal insecurity among the claimants in order to make sure they become even more submissive. This front-line policy is, first and foremost, concretely visible through the obstacles foreigners encounter when they submit their files. The bureaucracy has also evolved to conform to New Public Management, and street-level bureaucrats are subjected to a neoliberal disciplinary regime that has a substantial impact on the way streetlevel bureaucrats exercise discretion.

\section{Fuelling Juridical Insecurity}

Whereas the dematerialization of forms is praised as a way to rationalise and simplify procedures, it entails more difficulties for foreigners. The requirement to apply online poses an obstacle for foreigners and often hinders their access to prefecture front-line desks.

Foreigners who have just arrived in France are kept in juridical insecurity, that is to say they have no idea about how the law will be applied to their case. When migrants succeed in reaching a front-line desk to request or renew a residence permit, they have no means of knowing if they will leave the room with a renewed residence permit, a notification, or an order to leave the country. Migrants feel lost among a series of processes and rules; they do not understand the logic and language of bureaucracy. When they challenge a decision, they are usually reminded that they are not French citizens. They face powerful street-level bureaucrats who do not always know the law but who are entitled to impose their own interpretation of the circulars. Most of the time, the office managers instruct them in how to read the circulars, which implies huge variations from one district to another. The implementation of the law depends on a set of local characteristics that are indeed at the heart of the legal decision process. The discrepancy between instructions as written in circulars and the way they are applied on the field has always been significant in French immigration policy, but nowadays it appears to have widened. During the thirty-year post-war boom, immigration was not seen as a political issue and the vast majority of the circulars remained inside the bureaucratic sphere, out of range of public opinion. The aim of those circulars was essentially to standardise civil servants' practices across the territory. But since the beginning of the 1980s, immigration has become a political issue and is more and more present in the public debate (Laurens 2009). Most of the circulars are now 
released and accessible to the public; some of them are appealed in court and can fuel the political debate about immigration. The high-ranking civil servants who write those circulars are thus obliged to use euphemisms, allowing street-level bureaucrats to interpret them and to apply what they could not explicitly express.

Of course, every personal story is unique and each case reveals its own particular situation. But by connecting stories with the political context, the systematic suspicion raised by the government services on foreigners becomes clearly visible. The legal decision-makers are so focused on tackling "fraud" that they constantly revive the image of migrants as a threat to national law and order and the integrity of the state. This fight has also become an obsession for street-level bureaucrats (Alpes and Spire 2014) each time they have to deal with the rights of foreigners, even those who have connections with French nationals. The suspicion quickly turns into an accusation, through expressions like "marriage of convenience" for spouses of French nationals, "paternity of convenience" for French children's fathers who apply for French citizenship. The connection between the fight against illegal immigration and protection of the state carries new meaning via an extensive vision of French sovereignty. In this representation of the world, families are seen as a legitimate institution that should be protected against any attempt to add foreign entities without the state's approval.

This argument regarding fraud is at the heart of a culture of suspicion that changes the meaning of every social and matrimonial migrant practice. Until the beginning of the 1990s, foreigners who applied for citizenship for their children were viewed as wanting to integrate into French society. Nowadays the same claim is understood, in the eyes of high-ranking civil servants, as an attempt to break the law. Likewise, the increasing number of marriages between French nationals and foreigners used to be considered an "indicator of integration" but today, it is perceived as the revival of "marriages of convenience". This rhetoric of suspicion put in place by politicians and widely broadcast in the media has found multiple responses in immigration control services.

While for many claimants the ten-year-long resident permit, created in 1984, represented the first step on the path to integration in France, it has now become the ultimate reward in a hurdle race. In fact, among the foreigners entitled to live in France in 1994, more than $40 \%$ were granted a ten-year-long permit, but since 2013, the rate has fallen to less than 10\% (Math and Spire 2014).

This decrease in the number of long-term residence permits is the result of both increasingly restrictive legislation and a culture of suspicion that consists in reinterpreting any migrants' behaviour as possible fraud. Little by little, this culture of suspicion permeates other state agents involved in the same campaign against illegal immigration, even if they are not officially in charge of controlling immigration. For instance, the physicians who work for the Ministry of Health France are coming under tighter and tighter government surveillance when they must provide medical expertise on the health of migrants who are at risk of deportation. Labour inspectors are also increasingly recruited by the authorities to track down undocumented foreigners, even if those workers are proportionately seldom involved in breaking labour laws.

The public agencies engaged in tackling unemployment are also participating more and more in this spiral of repression. This recruiting of state agents against illegal immigration is not necessarily based on official government orders; it seeps 
insidiously into professionals' and street-level bureaucrats' behaviours, who had previously not been involved in migratory flow control. Increasingly, people who work with foreigners endorse this culture of suspicion by showing their willingness to crack down on fraud. This growing action against foreigners produces individual resistance and collective protests among some immigration agents, but it can prove effective among isolated agents who are less protected by their status or who are convinced by the aim of tackling illegal immigration.

This front-line policy has the effect of keeping foreigners in an insecure and vulnerable position, which increases the rate of foreigners who do not demand their rights (Waris 2012). First, foreigners belong to the weakest and most precarious fringe of the workforce; they are less capable of dealing with legal complexities and French bureaucracy. Poor housing conditions, lack of education and disorientation are among many social factors that keep foreigners from enjoying their due rights, especially when they are faced with complex files and forms to fill in. The second series of reasons is found in their status "alien": they must comply with a set of rules, like submitting requests for asylum, work permits, state medical aid or citizenship application. In all immigration control services, the discretionary power given to the street-level bureaucrats weakens the migrants' demand for their rights.

This front-line policy also accentuates discrepancies that are clearly noticeable from one desk to another, such as refusing to register a file, postponing a decision or compelling a claimant to register under a specific status. The implementation of a law or a circular depends essentially on how office managers explain the content of the text to their subordinate staff. Furthermore, inside the same department, the street-level bureaucrats do not necessarily apply the same meaning to management's instructions. The agent who examines a case refers to legal criteria, but the decision also depends on their background, that is to say on their professional status, seniority in the job and career. Differences between one service and another are heightened by the discretionary power given to street-level bureaucrats. Uncertainty and arbitrariness have thus become central elements in the relationship between migrants and the French state.

\section{Discretionary Power and New Public Management}

In the 1990s, New Public Management methods were imported into France. They have substantially impacted the bureaucracy and implementation of the law: the traditional rule-based, authority-driven processes have been replaced with marketbased, competition-driven tactics (Kettl 2005). In the field of immigration, performance objectives have been implemented to intensify the crackdown on illegal immigration. This evolution has made substantial impacts on discretionary power (Bastien 2009). The Minister of the Interior (the Home Secretary) focuses on the annual number of illegal immigrants deported, but this immigration policy of "setting target figures" stems not from any law but from oral instructions imposed on prefecture officials. Since 2002, the main issue regarding immigration policy has been how to accelerate and rationalize deportation procedures. Unlike other immigration services, this activity has been substantially subsidized. Target figures are assigned to the police force in terms of arrests, and to street-level bureaucrats in terms of "producing" deportation measures. Increasing expulsion capacities have been rendered possible thanks to reforms in the organizational work. State agents in charge of arresting undocumented migrants now pass on files to their colleagues 
in prefectures who immediately decide on the deportation of the migrant, who can be detained in custody for up to 45 days. This tougher repression of illegal immigration is in constant conflict with the legal guarantees theoretically afforded to asylum seekers based on rule of law principles. But each street-level bureaucrat is in charge of one task, and this specialization has effectively alleviates their responsibility. The expression "we are simply a cog in the administrative machinery" is frequently used by agents who play an active role in implementing migrant deportation.

Agents in charge of controlling migrants are not the only ones to focus their tasks on illegal immigration crackdown. Other civil servants are often summoned to assist them. For example, doctors in charge of delivering certificates on the health of undocumented migrants expecting medical treatment are being ever more closely monitored. Historically, the role played by doctors who work for the administration has always been for the benefit of public health, not to decide on individual cases. However, over the last few years, doctors have more frequently been asked to tackle illegal immigration.

The enlistment of civil servants does not necessarily depend on official instructions or directives but emerges thanks to encounters with prefecture agents who openly speak out about immigration. Through informal discussions, public health agents adapt their medical mission to a role of immigration control. Other civil servants whose jobs, in principle, have nothing to do with immigration policies are also progressively enlisted to support the crackdown on undocumented migrants. Health and safety inspectors are for instance often recruited because they are the only state agents allowed to enter businesses without holding a legal search warrant. Civil servants in charge of unemployment are also involved: they systematically have to provide prefectures with a copy of the residence permit of any foreigner looking for a job.

The control of illegal immigration has tightened in all countries across the European Union over the last three decades; in France, this trend has resulted in an unprecedented number of deportations and a full restructuring of state immigration offices. Such a policy is based on a new institution network that aims to enlist more civil servants in the surveillance of illegal immigration. This immigration policy based on quantified objectives has also brought about a steep increase of appeal cases in court. To deal with the increase in deportations, associations and groups who help undocumented migrants focus their tasks on the legal follow-up of each claimant.

\section{The Role of Legal Intermediaries}

In the immigration field, legal intermediaries play a crucial role when they help foreigners resist the discretionary power used by street-level bureaucrats. Intermediaries are sometimes legal professionals such as lawyers, but they can just as well be non-professionals such as volunteers, social workers, associations, or activists. Campaigning for the rights of undocumented migrants, they share files, meet in social places or gather online via forums that specialize in immigration (Siméant 1998). Whether social or professional, these actors seem to be convinced that the law is an indispensable tool to defend migrants' rights and can be viewed as co-producers of immigration policy (Ellermann 2009). Since the end of the 1980s, association members committed to helping migrants have invested in the 
legal field and given the priority to legal battles. Likewise, political activists, who have fought for the rights of undocumented migrants, have also been involved in this legalization process between the state and foreigners. Among the actors helping migrants, the line between informed amateurs and legal professionals is blurred; both work in very similar contexts and sometimes have equivalent knowledge of the law. In detention centres, social activists - such as Cimade, whose representatives are physically present in detention centres - have been involved in the designing several institutional reforms (Fischer 2017). Some of these activists are actually more knowledgeable about the immigration laws than court-ordered counsels who, because of their lack of practice in these matters, may be less wellversed in immigration policies. The more frequent use of legal tools by the associations who defend undocumented migrants does not mean that they always go to court. Associations frequently deter migrants from claiming documents when they know that the claim will be dismissed, and they also advise people whose file does not fit with asylum criteria to stay "under the radar" (Broeders and Engbersen 2007).

Lawyers also play an important role in resisting discretionary power. Some of those who regularly plead cases linked to immigration are or were members of associations who defend migrants' rights. The link between legal cases and political causes, highlighted by the cause lawyering literature (Sarat and Scheingold 1998 and 2001), needs to be nuanced for two main reasons: first of all, lawyers who specialize in the defence of migrants may, as a matter of fact, be profit-driven and therefore plead many cases, which implies that they are somewhat disengaged from the cause they claim to be defending. Furthermore, their need to find new clients sometimes puts them in direct competition with NGOs or activists. Ultimately, lawyers can do their job in three different ways: full-time advocacy as a "political cause", as "a humanitarian cause" pleaded from time to time, or as a mere profitmaking task without any political or moral consideration.

Taking legal intermediaries into account allows us to avoid a binary perspective that would be reduced to the interaction between state agents and migrants. Foreigners seldom have the necessary resources to deal with the discretionary power of street-level bureaucrats. The intervention of legal intermediaries, unevenly distributed across French territory, alters this power struggle. Their work does play an important role in how discretionary power is implemented.

\section{Conclusion}

Studying discretionary power in the immigration field evidences the many variations in how laws are enforced. The first criterion of treatment inequality can be found in how tasks and services are organized. In the immigration field, the scarcity of material and human resources allocated to services in charge of welcoming migrants contrasts starkly with the expenditure incurred to deport foreigners. Inequality also arises from how agents perceive users and the leeway they have to implement the law. A third type of inequality is related to the foreigners' abilities and means to challenge discretionary power, especially by the legal tools they use or through legal intermediaries that will help them.

The front-line policy has increasingly been used as a weapon against migrants, especially since the early 2000 s, when immigration and detention policies were 
generalized in France (Fischer 2013). More broadly, in Europe as well as in United States, immigration reforms have made greater use of detention and focused on enforcement rather than on hosting programmes and services for asylum seekers (Welch and Schuster 2005). But the reforms have also strengthened the role of legal intermediaries. Investigating how discretionary power is challenged sheds further light on the power relations between state agents and migrants. The confrontation is no longer limited to the bureaucratic sphere but tends to extend to other branches, such as courts and other public services.

\section{Notes}

${ }^{1}$ I use the phrase "selective closing of border" because some foreigners continue to be entitled to enter the territory if they are considered useful for the French economy or if they have been recognized as refugees.

${ }^{2}$ In the French hierarchy of the sources of law, the circular is at the very bottom of the scale of legal texts. It is below the decree, which is below the law, which itself has a lower value than international texts. A circular has the same value as a memorandum and can always be challenged in administrative court.

${ }^{3}$ On the gap between speeches and practices in case of racism, see Deutscher (1973).

${ }^{4}$ On this topic and more specifically on the history of immigration control in France, see Spire (2005).

${ }^{5}$ Hughes (1956).

${ }^{6}$ That's the same case at the Mexico-United State Border where "the principal thought work mechanism is the division of immigrants into illegal but honest workers and immoral drug and alien smugglers" (Mc. Heyman 1995:379).

\section{References}

Allison, G.T. and Halperin, M.H. (1972). Bureaucratic politics: A paradigm and some policy implications. World politics 24: 40-79. https://doi.org/ $10.2307 / 2010559$

Alpes, J. and Spire, A. (2014). Dealing with Law in Migration Control: The Powers of Street-level Bureaucrats at French Consulates. Social \& Legal Studies 23(2): 261-274. https://doi.org/10.1177/0964663913510927

Bastien, J. (2009). Goal ambiguity and informal discretion in the implementation of public policies: the case of Spanish immigration policy. International Review of Administrative Sciences 75(4): 665-685. https://doi.org/ 10.1177/0020852309351472

Bergman, W. (1992). The Problem of time in Sociology. Time and Society 1(1): 81134. https://doi.org/10.1177/0961463X92001001007

Bigo, D. (2014). The (in)securitization practices of the three universes of EU border control: Military/Navy-border guards/police-database analysts. Security Dialogue 45(3): 209-225. https://doi.org/10.1177/0967010614530459

Bourdieu, P. (1987). The force of law: toward a sociology of the juridical field. Hastings Law J. 38: 805-853. 
Bourdieu, P. (1990). Droit et passe-droit. Le champ des pouvoirs territoriaux et la mise en œuvre des règlements. Actes de la recherche en sciences sociales 81(1): 86-96. https://doi.org/10.3406/arss.1990.2928

Bourdieu, P. (2003). Participant objectivation. Journal of the Royal Anthropological Institute 9(2): 281-294. https://doi.org/10.1111/1467-9655.00150

Broeders, D. and Engbersen, G. (2007). The fight against illegal migration: identification policies and immigrants' counterstrategies, American Behavioral Scientist 50(12): 1592-1609. https://doi.org/10.1177/ 0002764207302470

Calavita, K. (1992). Inside the state: The Bracero Program, immigration, and the INS. New-York and London, Routledge.

Calvey, D. (2008). The art and politics of covert research: doing situated ethics in the field. Sociology 42(5): 905-918. https://doi.org/10.1177/ 0038038508094569

Dahlberg, L. (2013). Unwelcome Welcome-Being 'at Home'in an Age of Global Migration, Law Text Culture 17(1): 44-82.

Davis, K. (1969). Discretionary justice: A preliminary inquiry. Baton Rouge, Lusianan State Universty Press.

Deutscher, I. (1973). What We Say/What We Do. Gleniew, Scott Foreman and Co.

Dubois, V. (2016). The bureaucrat and the poor: Encounters in French welfare offices. New-York and London, Routledge. https://doi.org/10.4324/ 9781315614205

Ellermann, A. (2009). States Against Migrants: Deportation in Germany and the United States. Cambridge NY: Cambridge University Press. https://doi.org/ 10.1017/CBO9780511626494

Engbersen, G. and Broeders, D. (2009). The state versus the alien: Immigration control and strategies of irregular immigrants. West European Politics 32(5): 867-885. https://doi.org/10.1080/01402380903064713

Fischer, N. (2013). The detention of foreigners in France: Between discretionary control and the rule of law. European Journal of Criminology 10(6): 692-708. https://doi.org/10.1177/1477370813495126

Fischer, N. (2017). Le territoire de l'expulsion. Lyon, Presses universitaires de l'ENS. https://doi.org/10.4000/books.enseditions.7707

Foucault, M. (1977). Discipline and punish: The birth of the prison. New-York, Vintage.

Galligan, D. J. (1990). Discretionnary Powers : a legal study of official discretion. Oxford: Clarendon Press. https://doi.org/10.1093/acprof:oso/9780198256 526.001 .0001

Goffman, E. (1956). The Presentation of Self in Everyday Life. Edinburgh. University of Edinburgh. Social Sciences Research Centre.

Hughes, E.C. (1952). The Sociological Study of Work. American Journal of Sociology 57(5): 423-426. https://doi.org/10.1086/221010

Hughes, E.C. (1956). Social role and the division of labor. The Midwest Sociologist 18(2): 3-7.

Hughes, E.C. (1984). The Sociological Eye: Selected Papers. New Brunswik and London, Transaction Publisher.

Kettl, D.F. (2005). The global public management revolution: A report on the transformation of governance. Washington DC, Brookings Institution. 
Laurens, S. (2009). Une politisation feutrée. Les hauts fonctionnaires et l'immigration en France. Paris, Belin.

Lipsky, M. (1980). Street-Level Bureaucracy: Dilemmas in the Individual in Public Services. New York, Russel Sage Fundation. https://doi.org/10.2307/1288305

Math, A. and Spire, A. (2014). Précarisation: la preuve par les chiffres. Plein Droit 102: 34-38. https://doi.org/10.3917/pld.102.0034

Mc. Heyman, J. (1995). Putting Power in the Anthropology of Bureaucracy: The Immigration and Naturalization Service at the Mexico-United States Border. Current Anthropology 36(2): 261-287. https://doi.org/10.1086/204354

Moore, W.E. (1963). Man, Time and society. New-York, John Wiley \& Sons, Inc.

Pedace, R. (2006). Immigration, Labor Market Mobility, and the Earning of NativeBorn Workers. The American Journal of Economics and Sociology 65(2): 313346. https://doi.org/10.1111/j.1536-7150.2006.00453.x

Sarat, A. and Scheingold, S. (1998), Cause Lawyering. Political Commitmenst and Professionnal Responsabilities. New York, Oxford University Press.

Sarat, A. and Scheingold, S. (2001). Cause Lawyering and the State in a Global Era. New York, Oxford University Press, 2001. https://doi.org/10.1093/ 0195141172.001 .0001

Siméant, J. (1998). La cause des sans-papiers. Paris, Presses de la FNSP.

Spire, A. (2005). Étrangers à la carte. L'administration de l'immigration en France (1945-1975). Paris, Grasset.

Spire, A. (2008). Histoire et ethnographie d'un sens pratique. In Arborio, A.-M., Choen, Y., Fournier, P., Hatzfeld, N., Lomba, C. And Muller, S. (eds.), Observer le travail (pp. 61-76). Paris: La Découverte.

Spire, A. (2012). Accueillir ou reconduire. Enquête sur les guichets de l'immigration. Paris, Raisons d'agir.

Warin, P. (2012). Non-demand for social rights: A new challenge for social action in France. Journal of Poverty and Social Justice 20(1): 41-53. https://doi.org/10.1332/175982712X626761

Welch, M. and Schuster, L. (2005). Detention of asylum seekers in the US, UK, France, Germany, and Italy: A critical view of the globalizing culture of control. Criminal Justice, 5(4): 331-355. https://doi.org/10.1177/ 1466802505057715 